\title{
New Characterizing Method of a 3D Parametric Lattice Structure
}

\author{
Rémi Edouard \\ CSIP/ICUBE - INSA Strasbourg \\ 24 bd de la Victoire \\ 67084 Strasbourg \\ France \\ Hicham Chibane \\ CSIP/ICUBE - INSA Strasbourg \\ 24 bd de la Victoire \\ 67084 Strasbourg \\ France \\ Denis Cavallucci \\ CSIP/ICUBE - INSA Strasbourg \\ 24 bd de la Victoire \\ 67084 Strasbourg \\ France
}

Engineering designers often adapt their design structure to the needs of functional requirements independently of the capacity of the designed technical system to offer innovative capacities. Based on the notion of contradiction brought from TRIZ theory (Russian acronym for theory of inventive problem solving), we have developed an approach to reversely build a parametric intelligent structure potentially solving a wide range of inventive problematic situations. The proposed structure relies on an elastic buckling instability. A parametric CAD (Computer-Aided Design) model of the structure was carried out and its behavior is studied with finite element analysis (FEA), driven by a design of experiments (DoE). In this article, a specific method of characterization and multi-objective optimization of the structure is offered. Our objective is to bring a method to allow an engineering designer to solve rapidly and inventively his contradictory requirement in adapting it to the industrial application sought for.

Keywords: Lattice structure, Inventive design, TRIZ, Optimization, Additive manufacturing

\section{INTRODUCTION}

Meta-materials are specific materials with special characteristics which cannot be found in natural materials. In this article, meta-materials are investigated for their specialresponses which offer new mechanical possibilities. Nowadays, material limitations are observed in industrial applications and these new types of material can open new ways of innovation in many applications. The evolution can be done with new lattice structures which are investigated to offer specific mechanical behaviors[1],[2]. This article studies an auxetic structure which means that the structure owns a negative Poisson's ratio. More exactly, a structure with zero Poisson's ratio (ZPR) is studied. This study relies on a structure with a snapping mechanism. In other words, the mechanism is built around an elastic buckling instability. Numerous 2D structures built around this phenomenon were studied [3], [4] and to complete the approach, 3D structures with a snapping phenomenon also analyzed [5], [6]. Moreover, the studied structure were is intended to be manufactured by additive manufacturing due to its complex shapes. Characterization of these types of structures can rely on traction or compression method with finite element analysis (FEA) or experimental aspect[7]-[10]. The structure model proposed is a new structure not already studied in the scientific literature (according to our state of art). A parametric CAD (Computer-Aided Design) model of the structure was carried out. And this, to study the impact of the geometric parameters of the structure on the mechanical responses. So, to study the

Received: July 2021,Accepted: September 2021

Correspondence to: Rémi Edouard

CSIP/ICUBE - INSA Strasbourg,

24 bd de la Victoire, 67084 Strasbourg, France

E-mail: remi.edouard@insa-strasbourg.fr

doi:10.5937/fme2104894E

(C) Faculty of Mechanical Engineering, Belgrade. Allrights reserved influence of the action parameters on the mechanical responses, this paper relies on a design of experiments (DoE) [11]-[13]. To exploit the DoE's results, we used the response surface methodology (RSM)[14]-[17] which shows the action of parameters' influence on the evaluation parameters.

In brief, with this article, a specific method is offered to implement the geometric parameters of a structure depending on the desired response for a selected application. Indeed, a method for a multiobjective optimization of this special structure is spotlighted[18]-[21]. Following this optimization step, contradictions in the studied system can be identified. To obtain an innovative solution and not a compromise of the evaluation parameters, the resolution of the contradictions is necessary.

The concept of contradiction was put forward by Genrich Altshuller and it is an important notion of the TRIZ (Russian acronym for theory of inventive problem solving)method[22]-[24]. To build this method, several thousand of patents were analyzed and finally, formalized principles of problem's solving were extracted. Generally, in an engineering problem solving, a compromise is adopted between the different product parameters. To obtain an innovative solution of the problem, the contradictions have to be solved [25], [26]. The contradiction concept relies on two subcategories: the technical contradictions and the physical contradictions. First, the technical contradiction relays the impossibility that the studied system can satisfy two specific features together. These output characteristics are called evaluation parameters. The physical contradictions are built around the physical origin of the conflict: the action parameters. An element of the system must have two different states to respond to the desired features together. In other terms, the physical contradiction is described with the action parameters 
which have to be in different states to respond to each evaluation parameter's desired state.

Initially, in the classical TRIZ method, the notion of contradiction is built with one action parameter with two levels and with two evaluation parameters. The first level of the action parameter improves the first evaluation parameter and degrades the second, whereas the second level of the action parameter degrades the first evaluation parameter and improves the second. So, there is the contradictory aspect. Nevertheless, this notion can lead to the elaboration of an important number of contradictions in a complex engineering problem. This results in the processing of only judicious contradictions according to the experts due to the complexity to treat all the contradictions with TRIZ method. Moreover, with this understanding, there is a segmentation of the initial problem with different contradictions with two evaluation parameters and one action parameter each time. There is not a global vision of the problem because the evaluations parameters are not considered in a simultaneous way. To group the results of contradictions, different approaches were studied[27], [28]. The concept of generalized contradiction was proposed[29]-[32]. This approach allows to spotlight a conflict with several evaluation parameters and not only with two of them as previously. This is the concept of generalized technical contradiction (GTC). Similarly, the notion of generalized physical contradiction (GPC) is developed to allow the building of physical conflict with several action parameters. In an innovative strategy with an engineering problem, contradictions have to be identified and thereafter solving of those can be performed with TRIZ based methods. This to open the innovation way.

TRIZ and TRIZ-based frameworks are robust methods for engineering problem solving. These methods can be applied directly in product designing[33]-[35]. Besides, they can be combined with other optimization techniques to increase their capacities. For example, some authors proposed to integrate Lean principles into the process of Inventive Design Methodology (IDM), one of the TRIZ-based frameworks. This integration helped to increase the agility of the IDM framework [36]-[40].

Concerning the applications of the studied structure, we can imagine a future utilization as a specific shockabsorber or as an air compressor even if other various possibilities can offer to us. Currently, the characterizing method of the structure is the predominant step. However, later research steps will be able to be carried out on a concrete application.

\section{MATERIAL AND METHODS}

The method used to obtain a multi-objective optimization of the structure proposed (see Figure 1) is described below. This method is based on a DoE which relies on FEA. Finally, an analysis of the DoE's results led to obtain the influence of the different input parameters on the output parameters and to realize a multi-objective optimization. Figure 2, we can see the approach followed in this paper.
To start with, we rely on an industrial need. In our case, it is more exactly a research aspect for a future industrial application due to an actual limitation of the materials on the market. The structure's definition consists of the choice of a global shape for the model. With the defined structure, it is important to choose appropriate action parameters and evaluation parameters to study and to characterize the structure. Then, a parametric CAD model of the structure was performed and preliminary simulations were carried out. The levels of the different factors of the DoE were chosen.

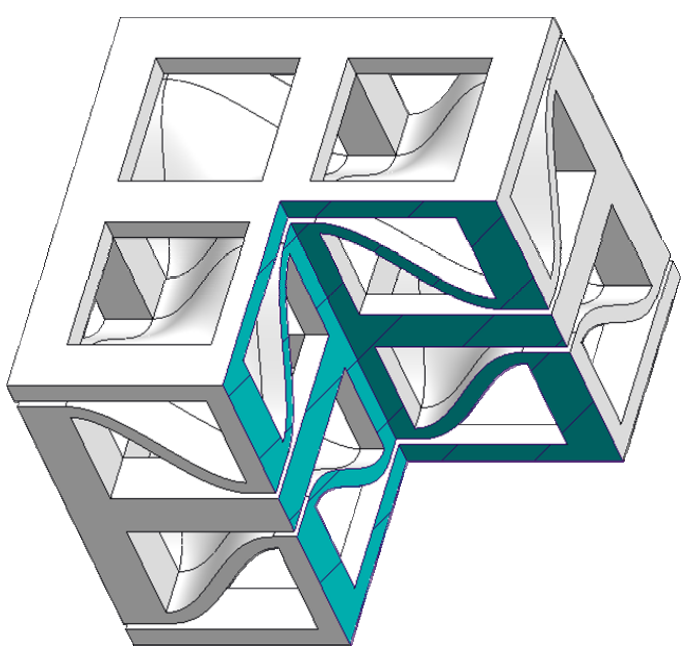

Figure 1. CAD model of the structure with a 3D cross section

Then, the numerical analyse were run according to the DoE. This allows to extract an experimental model. After this step, an optimization of the structure is proposed with different cases. If these optimizations are not acceptable for an industrial application, a new iteration of the method's first steps has to be performed or a new approach has to be led. This approach consists of the contradictions' spotlighting and with a typical method as inventive design or TRIZ method, the aim is to open the innovation way.

\subsection{Design of Experiments (DoE)}

The chosen structure is controlled by 3 parameters: $T_{1}, T_{2}$ and $L$. These parameters are shown in the Figure 3.

So, the DoE is composed of these 3 factors. We chose to study 3 levels for the factors $T 1$ and $T 2$ and only two levels for the factor $L$. This configuration of the DoE requires 18 experiences.

Furthermore, to build the model other parameters are needed. We chose to fix the gap noted $\alpha$ with a value of:

$$
\alpha=\frac{1}{24} L
$$

The snapping elements' length is defined as:

$$
A=L-T 2
$$

This is to respect variable parameters' values. The relation which defined the height of the snapping elements is the following: 


$$
B=L-T 2-2 \alpha-T 1
$$

In this way, the structure has a height of $2 L$ and a width and depth of $2 L+T 2$ which facilitates repetitionin space for a specific application. Indeed, an overlap is necessary for the repetition of the unitary model.

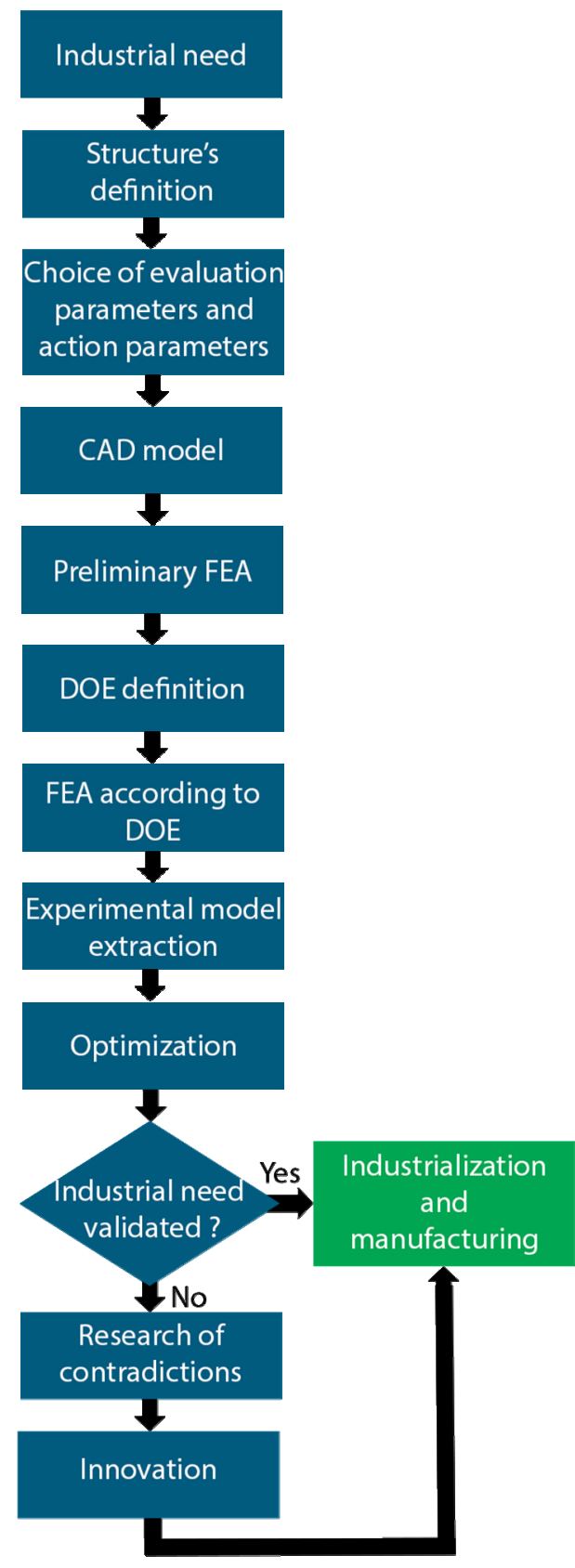

Figure 2. Diagram of the used method

To choose the values of the variable geometrical parameters $(T 1, T 2$ and $L)$ in the DoE, preliminary tests were performed with numerical simulations to check the convergence of the analysis. The finally chosen values of the geometrical parameters are (in millimeters):

- $T 1 \in\{0.8 ; 1 ; 1.2\}$

- $T 2 \in\{2 ; 3 ; 4\}$

- $L \in\{10 ; 12\}$

These values are visible in the Table 1.

After taking charge of the structure with primary simulations, we chose to study 4 output parameters also called evaluation parameters. The Poisson's ratio of the structure is analyzed to see the importance of the external deformations of the structure during istraction/compression. The maximum force needed to deform the structure activating the snapping mechanism is also studied. The maximum longitudinal deformation of the structure is considered. This is relies to know the maximum deformation of the model which on the ratio of the displacement of extremum points by the initial height of the structure. Furthermore, the viewable maximum stress of the structure is analyzed in comparison with the ultimate tensile strength. These evaluation para-meters are visible in Table 1 and there are respectively noted $v, F_{\max }, \in_{\max }$ and $\sigma_{\max }$.

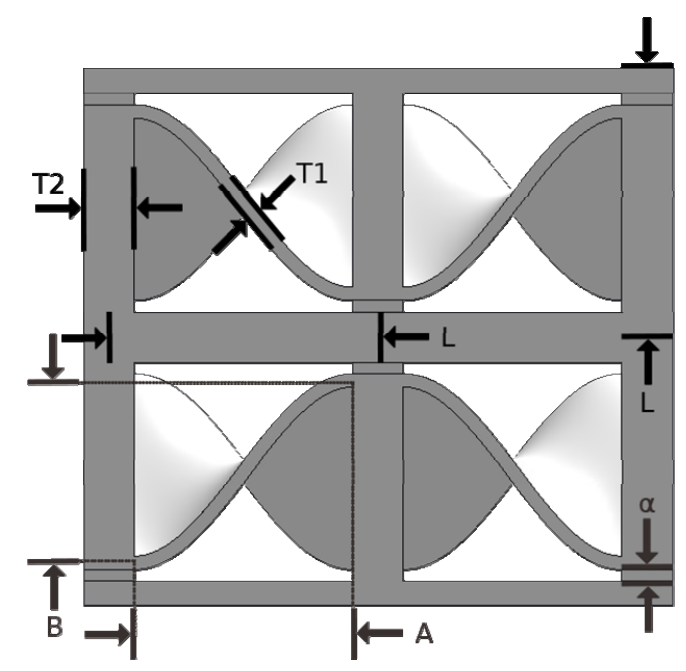

Figure 3. Geometrical parameters (front view)

\subsection{Finite Element Analysis (FEA): Structure modelling}

For this study, a 3D model of ZPR structure with snapping mechanism was chosen. First, a CAD model of this new structure was made with the software PTC Creo. The built model is completely parametric, driven by relations and parameters which is means that the geometric parameters can be changed and the CAD model will be regenerated automatically.

The structure is composed of 8 external symmetric snapping beams and also 4 internal symmetric snapping beams in two levels. These beams have U-shape defined by a trigonometric cosine function. Moreover, internal curved surfaces are added. This forms a double snapping mechanism with two levels. The snapping elements' shape is inspired of the deformation of an initial plane plate submitted to an imposed displacement of 4 areas and a fixed displacement on the 4 corner and the center of the opposite face. The shape obtained is illustrated in Figure 4.

The structure offers the possibility to be repeated in the three directions of space to perform a global structure with different characteristics. In this article, the unit structure is analyzed.

The complete 3D CAD model is built on a 2D model with one snapping element and two supporting segments. A symmetry was performed on this first design and then an axial repetition with 4 elements to form the top external snapping elements was made. The internal 
Table 1. Design of experiments

\begin{tabular}{|c|c|c|c|c|c|c|c|}
\hline \multirow{2}{*}{$\begin{array}{l}\text { Simulation } \\
\text { no. }\end{array}$} & \multicolumn{3}{|c|}{ Geometrical parameters } & \multicolumn{4}{|c|}{ Evaluation parameters } \\
\hline & $\begin{array}{l}T 1 \\
{[\mathrm{~mm}]}\end{array}$ & $\begin{array}{l}T 2 \\
{[\mathrm{~mm}]}\end{array}$ & & $V$ & $\begin{array}{l}F_{\max } \\
{[N]}\end{array}$ & $\epsilon_{\max }$ & $\begin{array}{l}\sigma_{\max } \\
{[\mathrm{MPa}]}\end{array}$ \\
\hline 1 & 0.8 & 2 & 10 & -0.0223 & 35.47 & 1.21 & 61.10 \\
\hline 2 & 1 & 2 & 10 & -0.0158 & 54.34 & 1.11 & 81.06 \\
\hline 3 & 1.2 & 2 & 10 & -0.0111 & 76.05 & 1.06 & 117.30 \\
\hline 4 & 0.8 & 3 & 10 & -0.0417 & 45.19 & 0.95 & 62.85 \\
\hline 5 & 1 & 3 & 10 & -0.0439 & 66.02 & 0.86 & 69.00 \\
\hline 6 & 1.2 & 3 & 10 & -0.0436 & 91.66 & 0.76 & 75.20 \\
\hline 7 & 0.8 & 4 & 10 & -0.0479 & 60.81 & 0.77 & 62.71 \\
\hline 8 & 1 & 4 & 10 & -0.0566 & 82.35 & 0.69 & 69.14 \\
\hline 9 & 1.2 & 4 & 10 & -0.0621 & 106.15 & 0.56 & 79.46 \\
\hline 10 & 0.8 & 2 & 12 & -0.0126 & 33.61 & 1.33 & 54.58 \\
\hline 11 & 1 & 2 & 12 & -0.0072 & 51.92 & 1.27 & 82.25 \\
\hline 12 & 1.2 & 2 & 12 & -0.0031 & 73.68 & 1.23 & 142.60 \\
\hline 13 & 0.8 & 3 & 12 & -0.0364 & 40.89 & 1.09 & 50.40 \\
\hline 14 & 1 & 3 & 12 & -0.0350 & 61.93 & 1.04 & 71.60 \\
\hline 15 & 1.2 & 3 & 12 & -0.0330 & 85.50 & 0.99 & 81.24 \\
\hline 16 & 0.8 & 4 & 12 & -0.0409 & 52.74 & 0.92 & 59.30 \\
\hline 17 & 1 & 4 & 12 & -0.0466 & 76.16 & 0.87 & 69.38 \\
\hline 18 & 1.2 & 4 & 12 & -0.0503 & 102.61 & 0.80 & 70.84 \\
\hline
\end{tabular}

snapping element with its supporting segments was drown and, in the same way, an axial repetition with 4 elements was carried out. To finish the top part, 2 extrusions were made to fill the 4 corners. Then, a symmetry of the previous steps was made to obtain the model without the internal curved surfaces. These surfaces were built with the surface mode and with a solidify method with the normal copied surfaces of the structure. The different CAD construction's steps are illustrated in the Figure 5.

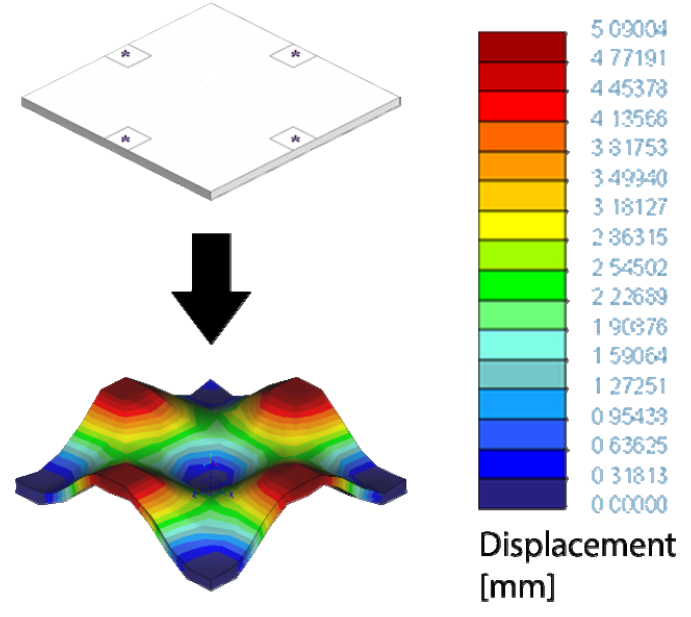

Figure 4. Deformation of a plate with the corners and the center fixed and a displacement imposed in 4 different areas in the opposite face (displacement [mm])

\subsection{Finite Element Analysis (FEA): Numerical simulations}

In this study, the behavior of the structure is analyzed by numerical simulations with Simulateextension of PTC Creo. First, concerning the limit conditions, the bottom surface of the structure is fixed and on the top surface a displacement is imposed. The traction speed is set to $3 \mathrm{~mm} / \mathrm{s}$. Concerning the material, we used a thermoplastic polyurethane (TPU) material with $\rho=$ $1250 \mathrm{~kg} / \mathrm{m}^{3}, \mathrm{E}=70 \mathrm{MPa}$ and $v=0.46$ where $\rho, \mathrm{E}$ and $v$ designate respectively the density, Young's modulus and Poisson's ratio of the material. The behavior of the material is set to linear elastic for all the simulations. An illustration of the traction of the structure with FEA is visible in Figure 6.

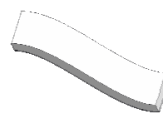

(1)

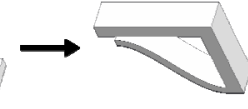

(2)

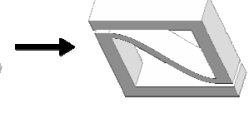

(3)

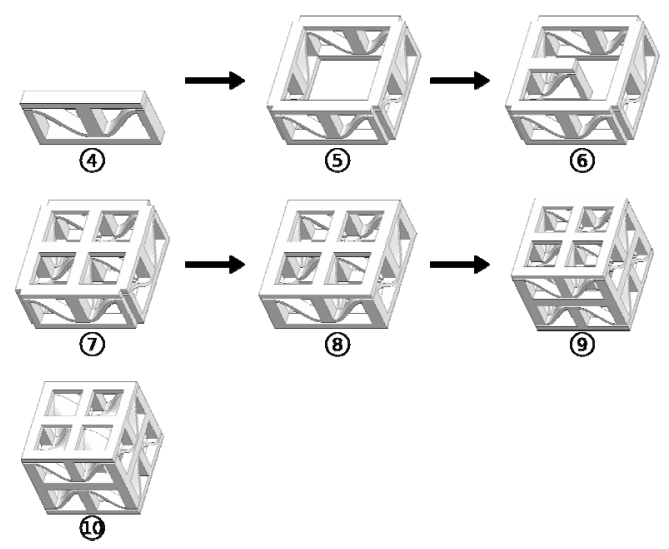

Figure 5. Designing of the CAD model

In the simulations, the longitudinal and traversal displacement of 4 points (see Figure 7) was studied to finally obtain the longitudinal and the transversal deformations of the structure. The transversal deformation is obtained from the measure of the transversal displacement of each point. First, the transversal length variation is calculated with the values of two point's displacement.Knowing the initial length between the two points, we can calculate the nominal deformation:

$$
\epsilon_{\text {nominal }}=\frac{\Delta L}{L_{0}}
$$


where $\Delta L$ is the transversal length variation and $L 0$ the initial length between the two points.

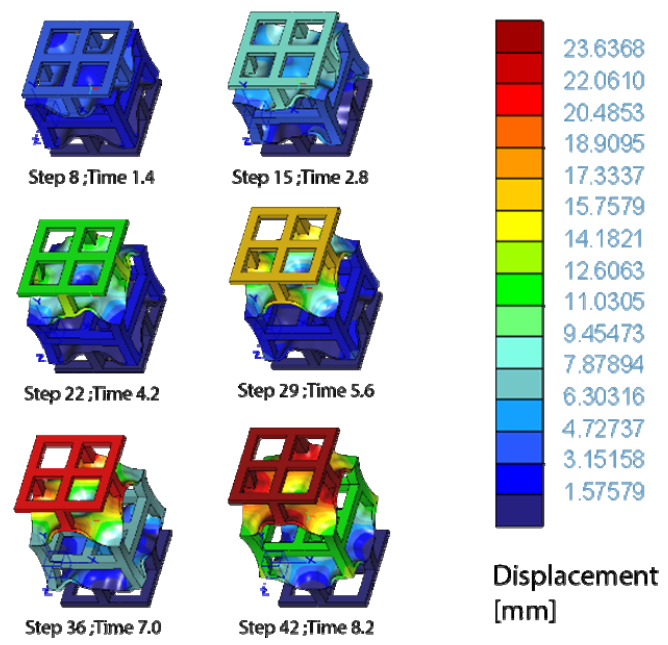

Figure 6. FEA - Evolution of the structure with $T 1=1 \mathrm{~mm}$; $T 2=3 \mathrm{~mm}$ and $L=12$ during traction (displacement $[\mathrm{mm}]$ )

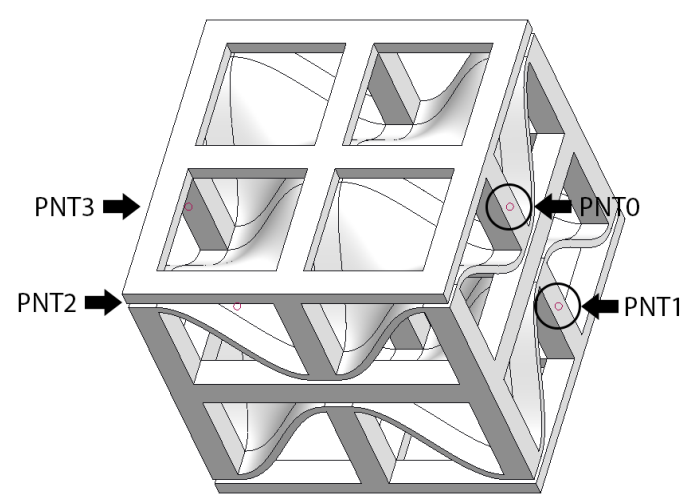

Figure 7. Position of the measuring points on the structure

The true deformation is also calculated, defined by:

$$
\epsilon_{\text {true }}=\ln \left(1+\epsilon_{\text {nominal }}\right)
$$

In our case, due to the little transversal deformations the two values are almsost identical. Next, the value of $\epsilon_{\text {true }}$ is used for other operations. The longitudinal deformation is calculated as the ratio of the longitudinal length variation by the initial height of the structure. Each calculation is done with a couple of two points and an average value of each results is calculated. For example, the transversal deformation is calculated with the couple of points $0 / 3$ and the couple of points $1 / 2$. For the longitudinal deformations, the couples of points $0 / 1$ and $2 / 3$ are used. Moreover, the results are calculated at each simulation's times steps. The number of steps for the simulation is defined in such a way the times step to be fixed to $0.2 \mathrm{~s}$. The Poisson's ratio is calculated at each step as the ratio of the transversal deformation and the longitudinal deformation. Moreover, our convention is to write a transversal length variation as positive if there is a dilatation of the structure and negative if the model is contracting. The longitudinal deformation is always positive (due to the displacement imposed). In this way, the sign of the Poisson ratio is defined by the opposite of the sign of the transversal deformation. In other words, if the average transversal length variation is positive, then the Poisson ratio would be negative and conversely.

Moreover, the snapping phenomena of the structure are illustrated in the Figure 8.

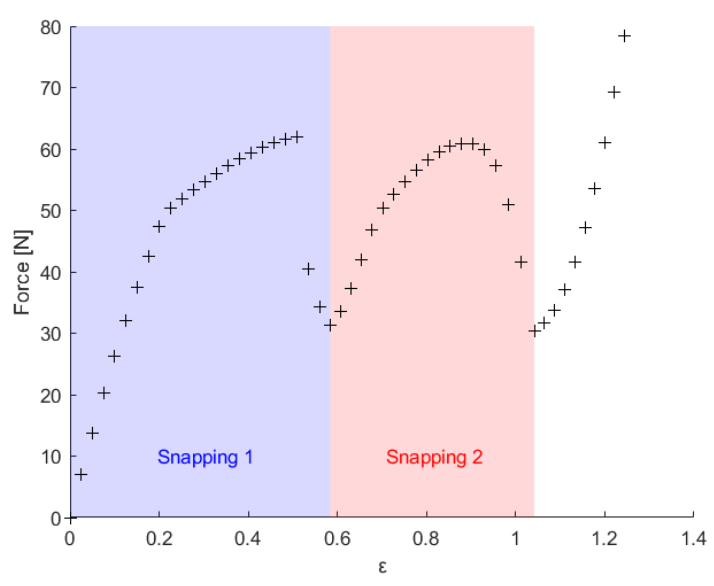

Figure 8. Evolution of the force needed to deform the model according to longitudinal deformation of the structure with $T 1=1 \mathrm{~mm} ; T 2=3 \mathrm{~mm}$ and $L=12 \mathrm{~mm}$

Indeed, as explained previously, the model is built around two levels with two curved snapping surfaces. In this figure, the force value needed to deform the structure according to the longitudinal deformation of the model is studied. We can see two extremmus which correspond to the deformation of each level of the structure defined by the snapping surfaces. According to this plot, the force value progressively grows and decreases in a prompt way twice. This event appears for each level of the structure and it is characteristic of the snapping phenomenon.

\section{EXPERIMENTAL PLANNING}

This section relates to Table 1 where $v, F_{\max }, \in_{\max }$ and $\sigma_{\max }$ are respectively the Poisson ratio average, the maximum traction force, the maximum strain and the maximum stress of the structure during only the snapping behavior. The geometrical parameters spotlighted in Table 1 are illustrated in Figure 3. The parameters $T 1, T 2$ and $L$ are expressed in milli-meters, $F_{\max }$ in Newtons and $\sigma_{\max }$ in Mega-Pascals.

To exploit the simulation results prescribed by the DoE, the software Minitab was used. A regression of each evaluation parameter was built. This, to express the evaluation parameters depending on the action parameters (the geometrical parameters). First, the regression was realized with all the full quadratic terms. Then, only the significant terms were retained relying on the p-value (Fisher's test). To simplify the model, we keep only the terms with a p-value lower than 0.05 . To simplify the model and to have regressions with only significant terms, we used an automatized stepwise method with a $\alpha$-value of 0.05 . This method carried out a variable selection by adding or deleting terms from the model based on the F-test. The variables are progressively added into the model or deleted according to the $\mathrm{p}$-value obtained in comparison with the chosen value of $\alpha$. So, the simplified stepwise regression model is visible in the Table 2 . 


\begin{tabular}{|l|}
\hline$v=-0.04391+0.08225 \times T 1-0.03716 \times T 2 \mathrm{~s}$ \\
$+0.004441 \times L+0.007569 \times T 2 \times T 2-0.02761 \times T 1 \times T 2$ \\
\hline$F_{\max }=-8.5+5.1 \times T 1+2.37 \times T 2+0.622 \times L+39.4 \times T 1 \times T 1+1.957 \times T 2 \times T 2+9.09 \times T 1 \times T 2-0.929 \times T 2 \times L$ \\
\hline$\in_{\max }=2.439-1.159 \times T 1-0.4760 \times T 2-0.0312 \times L+0.03587 \times T 2 \times T 2-0.0608 \times T 1 \times T 2+0.10892 \times T 1 \times L+0.00969 \times T 2 \times L$ \\
\hline$\sigma_{\max }=-110+307.02 \times T 1-2.8 \times T 2+10.76 \times T 2 \times T 2-72.5 \times T 1 \times T 2$ \\
\hline
\end{tabular}

Table 3. Analysis of variance (ANOVA) of Poisson's ratio v

\begin{tabular}{|c|c|c|c|c|}
\hline Source & $\mathrm{DOF}^{\mathrm{a}}$ & Adj $\mathrm{SS}^{\mathrm{b}}$ & $\operatorname{Adj} M^{c}{ }^{c}$ & F-value \\
\hline Model & 5 & 0.005325 & 0.001065 & 627.54 \\
\hline Error & 12 & 0.000020 & 0.000002 & \\
\hline Total & 17 & 0.005345 & & \\
\hline Term & Coded coef $^{\mathrm{d}}$ & SE coef ${ }^{e}$ & T-value & P-value \\
\hline Constant & -0.038991 & 0.000532 & -73.31 & $<0.0001$ \\
\hline \begin{tabular}{|l|}
$T 1$ \\
\end{tabular} & -0.000116 & 0.000376 & -0.31 & 0.764 \\
\hline$T 2$ & -0.019358 & 0.000376 & -51.47 & $<0.0001$ \\
\hline$L$ & 0.004441 & 0.000307 & 14.46 & $<0.0001$ \\
\hline$T 1 \times T 2$ & 0.007569 & 0.000651 & 11.62 & $<0.0001$ \\
\hline$T 1 \times T 2$ & -0.005522 & 0.000461 & -11.99 & $<0.0001$ \\
\hline
\end{tabular}

${ }^{\text {a }}$ Degrees Of Freedom

${ }^{\mathrm{b}}$ Adjusted Sums of Squares

${ }^{c}$ Adjusted Mean Squares

${ }^{\mathrm{d}}$ Coded coefficient

${ }^{\mathrm{e}}$ Standard Error of the coefficient

\subsection{Poisson's ratio}

In Figure 9, we can notice the comparison between the experimental values of the Poisson's ratio and values given by the simplified regression.

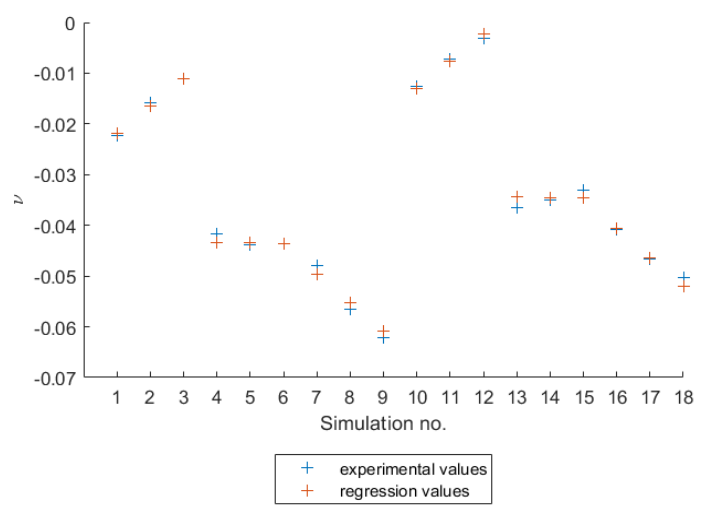

Figure 9. v: Comparison experimental values and regression values

The value of $R^{2}$ of this regression is $99.62 \%$. The higher this value, the better the model fits data. In our case, this value means that $99,62 \%$ of the Poisson ratio variation is explained by the model and that only $0,38 \%$ is unexplained. We can say that the model used is a good approximation of the Poisson ratio.

In this section, we will detail one case of the analysis of variance (ANOVA) with the parameter of Poisson's ratio $v$. The approach is similar to the other evaluation para-meters, so we will not detail the ANOVA of maximum traction force $F_{\max }$, maximum strain $\epsilon_{\max }$ or maximum stress $\sigma_{\max }$. The ANOVA study was performed with a confidence interval of $95 \%$, i.e with a value of $\alpha$ of $5 \%$. The results of ANOVA are showed in Table 3 .

The F-value calculated for the model is 627.54. This means that the part of variance of the Poisson's ratio explained by the model is 627.54 times larger than the part of variance that remains unexplained. Moreover, the p-value of the model is smaller than 0.0001 . This value means that the probability that the model is not significant is smaller than $0.01 \%$. In other words, this possibility is negligible. In Figure 10, the influence of the different terms in the regression of the Poisson ratio is shown. Normalized values are used to build this bar chart and to compare the variables. In this comparison, $T 2$ has the largest impact on the Poisson ratio but other terms' influences are present.

To analyze the influence of the different action parameters on the responses of evaluation parameters, we plotted the surface response charts of each case. The Figures 11 and 12 show that $T 2$ has more influence on the Poisson ratio in comparison with $T 1$ and $L$.

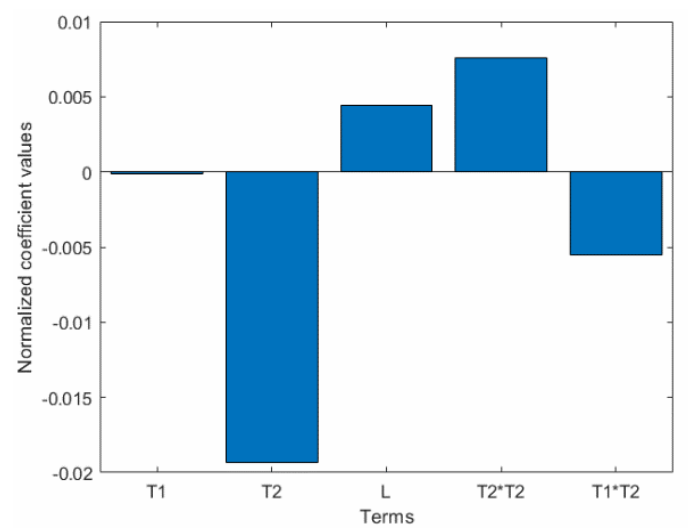

Figure 10. $v$ : normalized regression values 


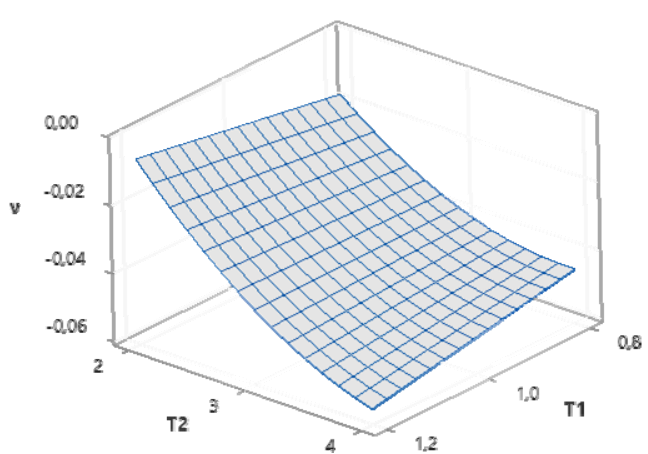

Figure 11. Surface plot of $v$ and $T 1 ; T 2$ (for $L=11 \mathrm{~mm}$ )

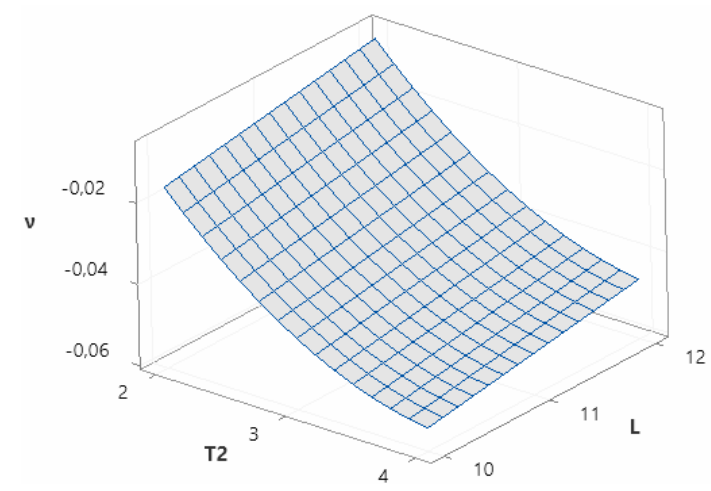

Figure 12. Surface plot of $v$ and $T 2 ; L$ (for $T 1=1 \mathrm{~mm}$ )

Moreover, the lower T2, the nearer the Poisson's ratio is to zero. And,the higher $T 1$ and $L$, the nearer the Poisson ratio is to zero, even if these two parameters have a minimal influence.

\subsection{Maximum traction force}

In the same way, a regression of the maximum traction force was established according to the action parameters.

In Figure 13, we can see a comparison between the experimental values of the maximum traction force and values given by the simplified regression.

The value of $R^{2}$ of this regression is $99.89 \%$. This value means that $99.89 \%$ of the maximum traction force variation is explained by the model and that only $0.11 \%$ is unexplained. The regression model is sufficient.

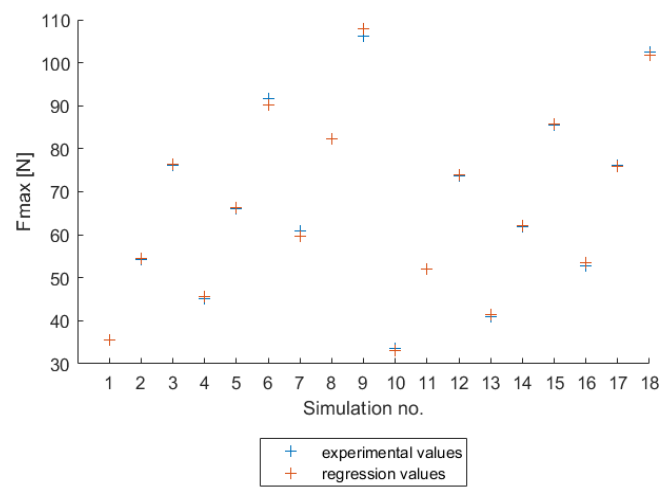

Figure 13. $F_{\text {max }}$ : Comparison experimental values and regression values

Figure 14 expresses that the higher $T 1$ and $T 2$, the higher the traction force needed to deform the structure is. As we can see in Figure 15 the influence of $L$ on the maximum force of traction is not very important.

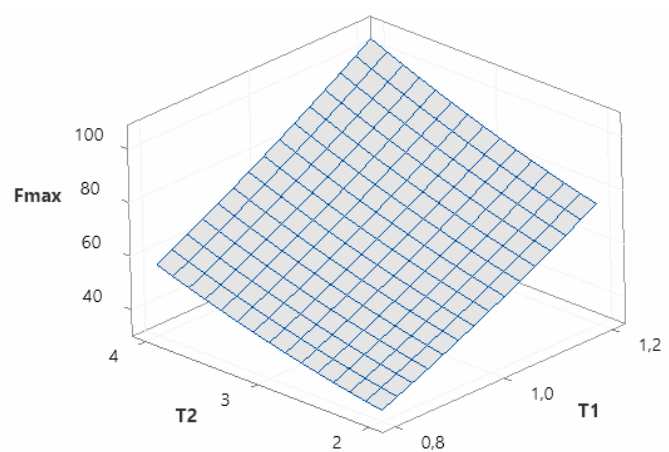

Figure 14. Surface plot of $F_{\max }$ and $T 1 ; T 2$ (for $L=11 \mathrm{~mm}$ )

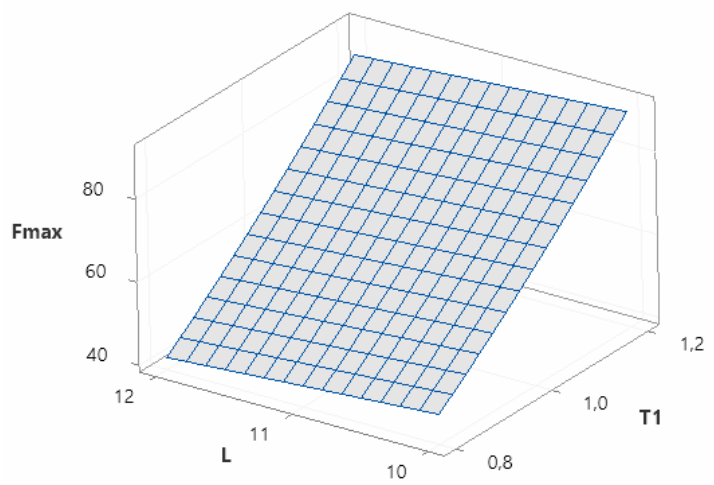

Figure 15. Surface plot of $F_{\max }$ and $T 1 ; L($ for $T 2=3 \mathrm{~mm}$ )

\subsection{MAXIMUM STRAIN}

In the Figure 16, we can catch sight of a comparison between the experimental values of the maximum strain of the model and values given by the simplified regression. The value of $R^{2}$ of this regression is $99.84 \%$. This value means that $99.84 \%$ of the maximum deformation variation are explained by the model and that only $0.16 \%$ are unexplained. The approximated model is largely correct.

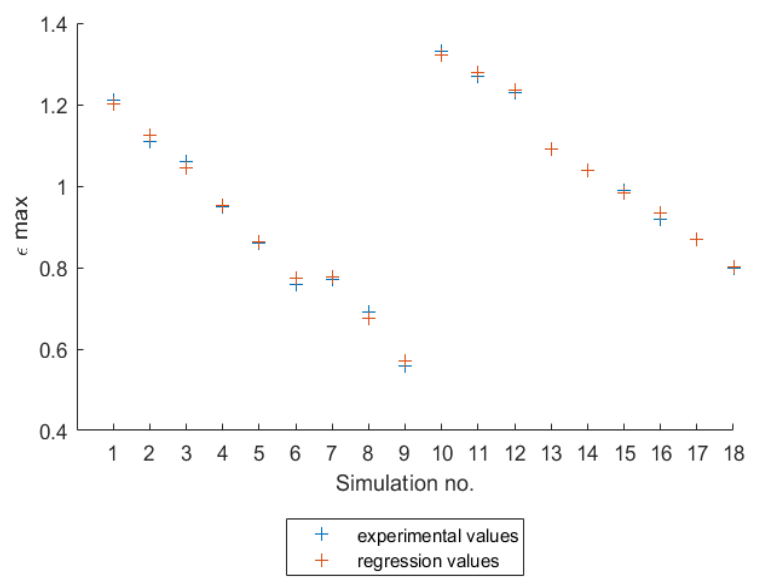

Figure 16. $\epsilon_{\max }$ Comparison experimental values and regression

As shown in Figures 17 and 18, T2 is the para-meter which has the most important influence on the maximum deformation. The lower $T 2$, the higher the maximum deformation is. Furthermore, the lower $T 1$, the higher the maximum deformation of the structure is. And, if the parameter $L$ is important, then the maximum deformation will be important. 


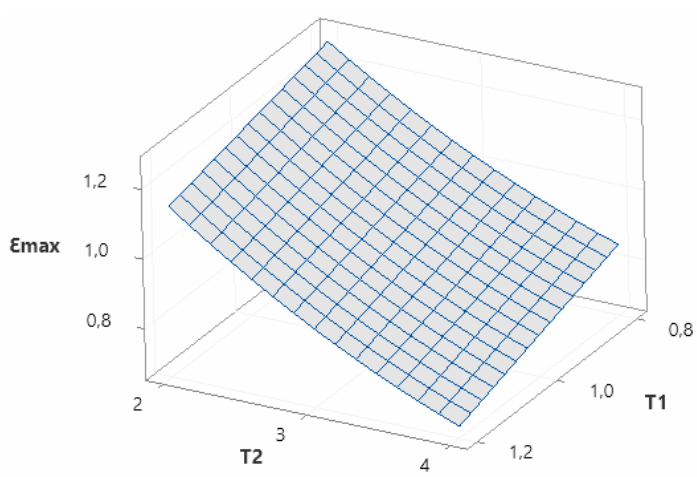

Figure 17. Surface plot of $\in_{\max }$ and $T 1 ; T 2$ (for $L=11 \mathrm{~mm}$ )

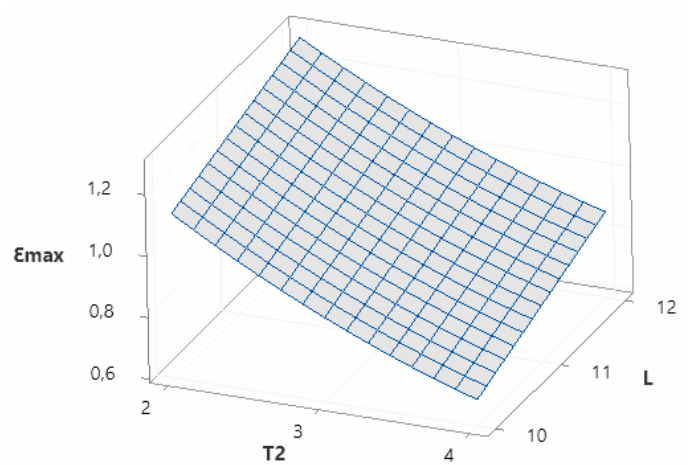

Figure 18. Surface plot of $\in_{\max }$ and $T 2 ; L$ (for $\left.T 1=1 \mathrm{~mm}\right)$

\subsection{Maximum stress}

In Figure 19, we can notice the comparison between the experimental values of the maximum stress in the structure and values given by the simplified regression.

The value of $R^{2}$ of this regression is $88.02 \%$. This value means that $88.02 \%$ of the maximum stress variation of the structure during traction is explained by the model and that $11.98 \%$ is unexplained. This regression is not as good as the other models. However, this regression remains acceptable.

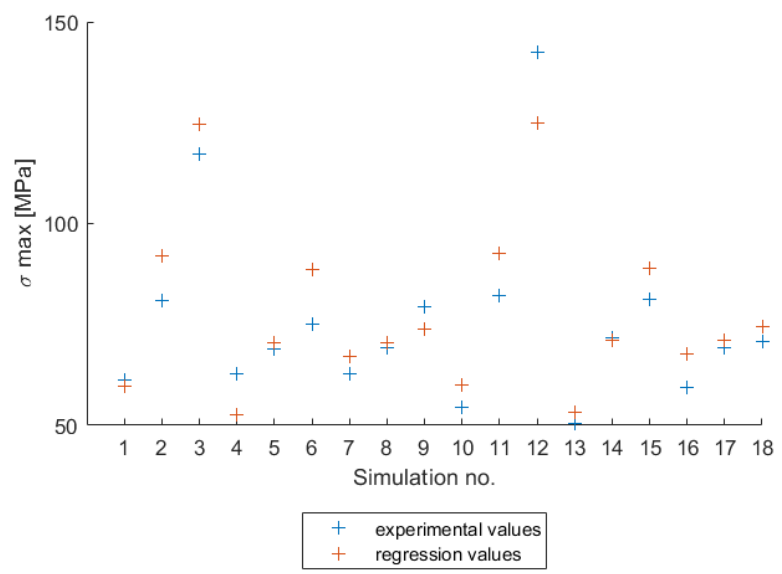

Figure 19. $\sigma_{\max }$ Comparison experimental values and regression values

The value of the stress is maximum when $T 1$ is important and $T 2$ is small (see Figure 20). The influence of $L$ on the stress of the structure is minimal as we can see in Figure 21. We can underline a major quad-ratic aspect, unlike the previous surface plots where the linear aspect was predominant.

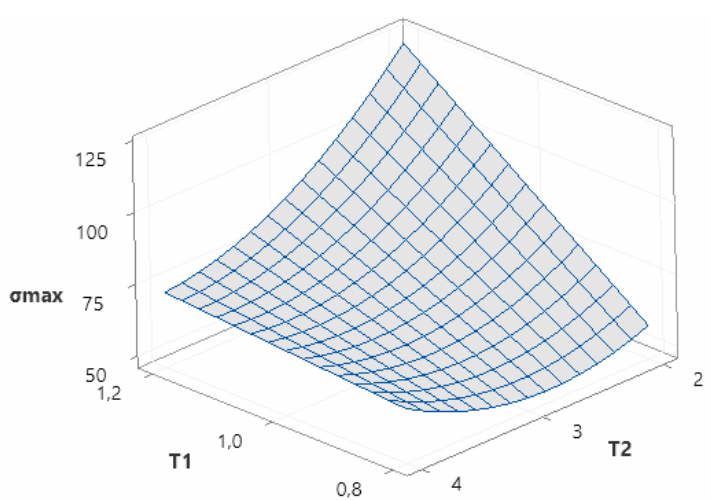

Figure 20. Surface plot of $\sigma_{\max }$ and $T 1 ; T 2$ (for $L=11 \mathrm{~mm}$ )

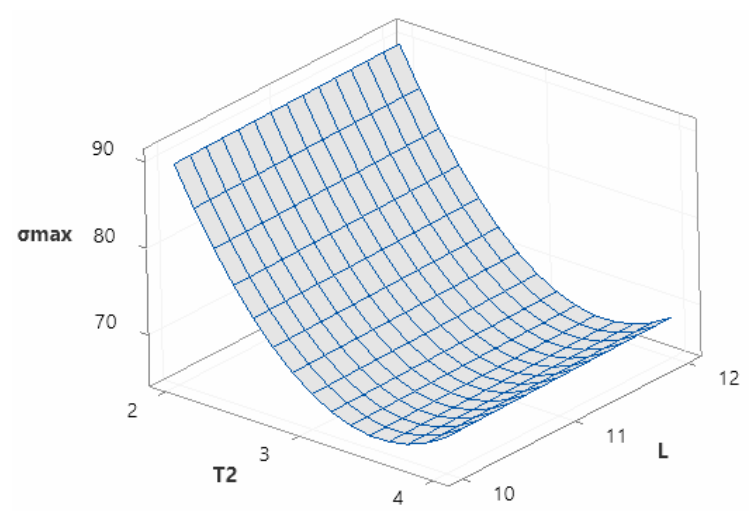

Figure 21. Surface plot of of $\sigma_{\max }$ and $T 2 ; L($ for $T 1=1 \mathrm{~mm})$

\section{OPTIMIZATION}

\subsection{Mono-objective optimization}

In this section, we search to optimize one evaluation parameter independently of the others. The objective functions were built from the previous regression for each evaluation parameter and we desire to minimize or maximize these functions. The considered objectives are the following for example:

- To maximize the Poisson ratio $v$ to obtain a value near to zero;

- $\quad$ To maximize the maximum traction force $F_{\max }$;

- To maximize the deformation of the structure $\epsilon_{\text {max }}$;

- To minimize the maximum stress in the structure $\sigma_{\max }$.

TheGODLIKE (Global Optimum Determination by Linking and InterchangingKindred Evaluators) algorithm developed by RodyOldenhuis with Matlab was used to perform these mono-objective optimizations. This algorithm combines different calculation methods:

- Genetic Algorithm (GA)

- $\quad$ Particle Swarm Optimization (PSO)

- $\quad$ Adaptive Simulated Annealing (ASA)

- Differential Evolution (DE)

In Table 4, the optimized evaluation parameters are visible with the values of action parameters to obtain. Furthermore, in each row, the other evaluation parameters are calculated with the regression model. 


\subsection{Multi-objective optimization}

In this section, we will study several case examples to show the used method to perform a multi-objective optimization.

\section{Case 1 :}

In this case, we chose to maximize the Poisson ratio $v$ and the maximum deformation of the structure $\epsilon_{\max }$. We used the GODLIKE algorithm to optimize these two parameters.

In the figure 22 , the red dots designate the compromises to optimize the two evaluation parameters $v$ and $\epsilon_{\max }$.

The algorithm searched to minimize the objective functions and that is the reason why we use the inverse function of the parameter. Indeed, we want to maximize the evaluation parameters therefore to minimize the inverse function of the parameter. Moreover, in this figure, we can appreciate that the minimization of the function $F 1(x)$ involve the maximization of the function $F 2(x)$. The two objective functions have opposite objec-tives. This means that we can see a contradiction. Two solutions are possible, to optimize one parameter at the expense of the other and perform a compromise or to put forward an innovation to succeed the optimization of the two parameters.

To resume the case example 1, we performed a plot which shows an optimization of the parameters $v$ and $\epsilon_{\max }$. In this example, we want a value of $v$ upper than -0.03 and a value of $\epsilon_{\max }$ upper than 1. In Figure 23, the green area designates the values of $T 1$ and $T 2$ which respect the structure's condition to have a Poisson ratio higher than -0.03 and a maximum defor-mation higher than 1 (i.e. the maximum longitudinal deformation is higher than the initial height of the model). In other words, to respect these two conditions in the evaluation parameters, the values of the action parameters must be in the green area.

\section{Case 2 :}

In this new case, we want to maximize the traction force of the structure and to minimize the maximum stress of the model to be under the ultimate tensile strength of the chosen material.

Figure 24 illustrates the Pareto front of the variables $F_{\max }$ and $\sigma_{\max }$. The red dots designate the compromises to optimize the two evaluation parameters.

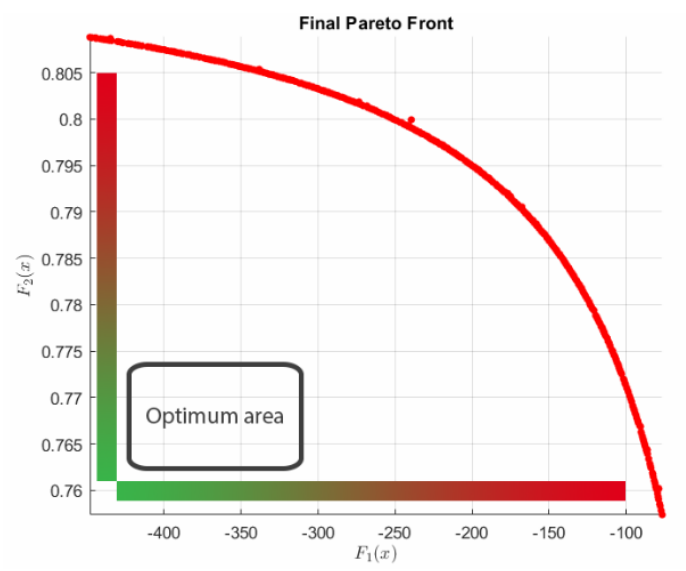

Figure 22. Pareto front with $F 1(x)=\frac{1}{v}$ and $F 2(x)=\frac{1}{\epsilon_{\max }}$

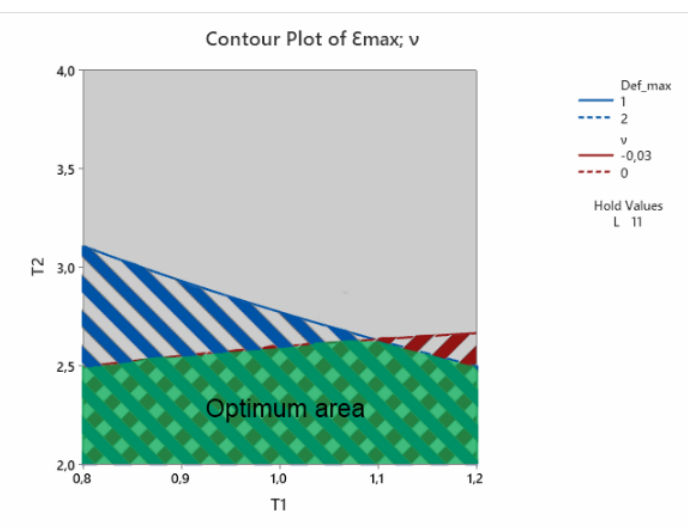

Figure 23. Contour plot of $v ; \in_{\max }$ and $T 1 ; T 2$

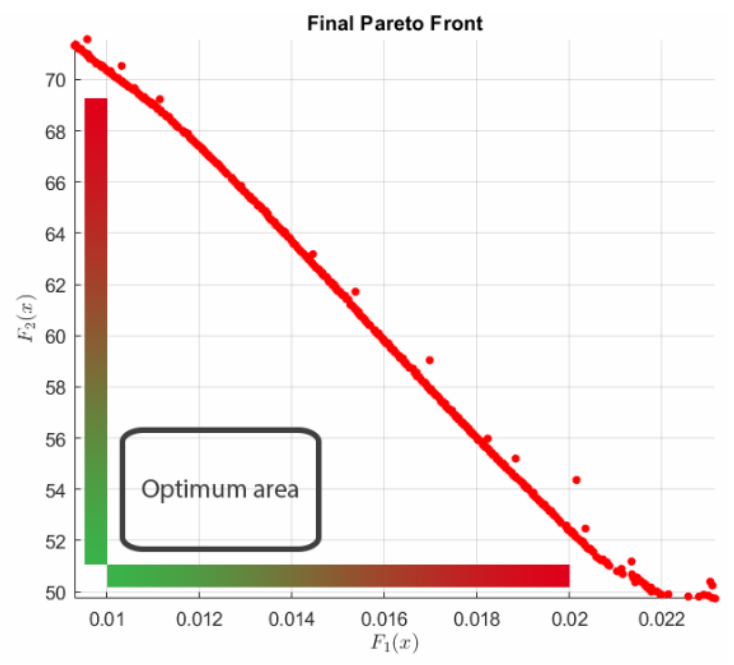

Figure 24. Pareto front with $F 2(x)=\sigma_{\max }$ and $F 2(x)=\sigma_{\max }$

Table 4. Mono-objective optimization

\begin{tabular}{|l|l|l|l|l|l|l|l|l|}
\hline \multirow{2}{*}{$\begin{array}{l}\text { Parameter } \\
\text { to optimize }\end{array}$} & \multirow{2}{*}{$\begin{array}{l}\text { Minimize } \\
\text { or maximize }\end{array}$} & $\begin{array}{l}T 1 \\
{[\mathrm{~mm}]}\end{array}$ & $\begin{array}{l}T 2 \\
{[\mathrm{~mm}]}\end{array}$ & & \multicolumn{4}{c|}{ Evaluation parameters } \\
\hline$v$ & maximize & 1.1998 & 2.0001 & 11.9979 & $\mathbf{- 0 . 0 0 2 2}$ & 73.89 & 1.24 & 122.22 \\
\hline$E_{\text {max }}$ & maximize & 1.2000 & 4.0000 & 10.0002 & -0.0608 & $\mathbf{1 0 7 . 8 4}$ & 0.57 & 71.30 \\
\hline$\epsilon_{\text {max }}$ & maximize & 0.8003 & 2.0003 & 11.9982 & -0.0130 & 33.11 & $\mathbf{1 . 3 2}$ & 57.42 \\
\hline$\sigma_{\text {max }}$ & minimize & 0.8000 & 2.8256 & 10.0000 & -0.0407 & 43.64 & 0.99 & $\mathbf{4 9 . 5 7}$ \\
\hline
\end{tabular}




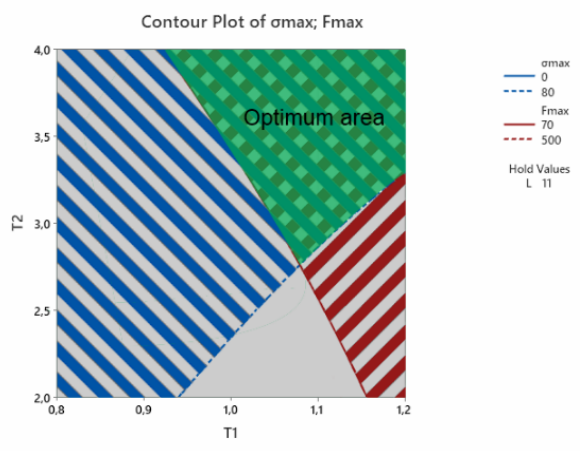

Figure 25. Contour plot of $\sigma_{\max } ; F_{\max }$ and $T 1 ; T 2$

In the same way, in Figure 25, the green area is the best values of the geometrical parameters $T 1$ and $T 2$ to obtain the chosen objective. If the action parameters have a value included in this optimum area, the maxi-mum stress of the structure will be lower than $80 \mathrm{MPa}$ and the force needed to extend the model will be higher than $70 \mathrm{~N}$.

In these two cases, we use only two parameters to optimize. However, more parameters can be added to obtain an optimization area.

\subsection{Optimization and contradictions}

In this section, we will study a complete case study with all the parameters. The smart lattice structure can be used as a shock absorber, for example. To be consistent with the previous steps of this study, we will spotlight a part of a vehicle bumper with a low speed shock.For this application, it is necessary to have specific levels of the different evaluation parameters:

- Poisson's ratio $v$ needs to be high (to be near to zero)

- Maximum traction force $F_{\max }$ needs to be high

- Maximum strain $\epsilon_{\max }$ needs to be low

- Maximum stress $\sigma_{\max }$ needs to be low

The Poisson ratio must have a value close to zero. In this way, the transversal deformation of the structure is limited in comparison with the longitudinal deformation applied on the vehicle bumper. The maximum traction force needed to deform the structure has to be important to collect the force of the bumper's external environment. The part of the bumper constituted of the lattice structure must have the smallest strain during the low-speed crash. This, to limit the global deformation of the part. The maximum stress in this structure has to be the smallest as possible to not damage the part and to be under the material limits.

To obtain these levels of the evaluation parameters, we studied the influence of the action parameters. For this, the main effect plots were performed for each evaluation parameter. With these plots, we determined the level needed of the action parameters to minimize or maximize the value of the selected evaluation parameter. The case of Poisson's ratio is showed in the Figure 26. To have a high value of $v$ as explained previously, we can see that $T 1$ has very few influences, $T 2$ must have a minimum value and $L$ has to be maximum. This result and the results of the other evaluation parameters are seen in the Table 5.
In Table 5, a 0 -symbol means that the action parameter is not influent on the evaluation parameter value. Moreover, a *-symbol means that the action parameter is very few influent on the result of the evaluation parameter.

When we analyze the results in Table 5 , we can point out that there is not a simple manner to obtain the desired objectives of the evaluation parameters with the levels of action parameters. Indeed, $T 1$ has to be maximum to be conform with a high value of $F_{\max }$ and a low value of $\epsilon_{\max }$ whereas $T 1$ has to be minimum to satisfy a low value of $\sigma_{\max }$. In the same way, $T 2$ must be maximum to respect $F_{\max }, \in_{\max }$ and $\sigma_{\max }$ desired levels and must be minimum to respect the high value of $v$. The parameter $L$ must be maximum to answer to the need of $v$ level whereas $L$ must be minimum to be conform with the level of $F_{\max }$ and $\epsilon_{\max }$. Following this observation, we decided to investigate the contradictions approach.

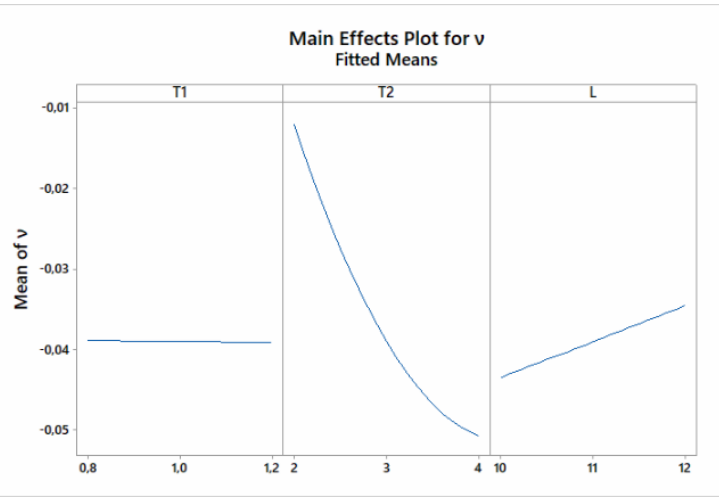

Figure 26. Main effects plot for $v$

Table 5. Levels of the action parameters needed to obtain the objectives on evaluation parameters

\begin{tabular}{|l|l|l|l|}
\hline $\begin{array}{l}\text { Evaluation } \\
\text { parameters : } \\
\text { objectives } \\
\text { chosen }\end{array}$ & \multicolumn{3}{|c|}{ Levels of action parameters needed } \\
\cline { 2 - 4 } & $T 1$ & $T 2$ & $L$ \\
\hline$N$ : high & 0 & $T 2_{\min }$ & $L_{\max }$ \\
\hline$F_{\max }:$ high & $T 1_{\max }$ & $T 2_{\max }$ & $L_{\min }{ }^{*} L_{\min }$ \\
\hline$\epsilon_{\max }:$ low & $T 1_{\max }$ & $T 2_{\max }$ & $L_{\min }$ \\
\hline$\sigma_{\max }:$ low & $T 1_{\max }$ & $T 2_{\max }$ & $\mathbf{0}$ \\
\hline
\end{tabular}

To spotlight the contradictions of our research, we studied the obtained values in the DoE. Concerning the method, previously we chose the states needed for each evaluation parameters to answer to the need of the vehicle bumper case study. We chose to rely on the average value of each evaluation parameter in the DoE to determine the compliance limit values' of the objectives. Indeed, in the case where the evaluation parameter must be maximum, all the obtained values of this parameter higher than the parameter's average in the DoE are valid and, according to our choice, responding to the need. Of course, this criterion can be modified to adjust the accuracy of the results and to optimally respond to the industrial need. Similarly, if the evaluation parameter must be minimum, all the values of this parameter in the DoE lower than the parameter's average in the same DoE will be acceptable. 
Table 6. Generalized systems of contradiction (GSC)

\begin{tabular}{|c|c|c|c|c|c|c|c|c|}
\hline & \multirow{2}{*}{$\begin{array}{l}\text { Simulation } \\
\text { no. }\end{array}$} & \multicolumn{3}{|c|}{ Geometrical parameters } & \multicolumn{4}{|c|}{ Evaluation parameters } \\
\hline & & $\begin{array}{l}T 1 \\
{[\mathrm{~mm}]}\end{array}$ & $\begin{array}{l}T 2 \\
{[\mathrm{~mm}]}\end{array}$ & & $v$ & $\begin{array}{l}F_{\max } \\
{[N]}\end{array}$ & $\in_{\max }$ & $\begin{array}{l}\sigma_{\max } \\
{[\mathrm{MPa}]}\end{array}$ \\
\hline \multirow{2}{*}{$\begin{array}{l}U_{0}- \\
\text { - }\end{array}$} & 6 & 1.2 & 3 & 10 & -0.0436 & 91.66 & 0.76 & 75.20 \\
\hline & 15 & 1.2 & 3 & 12 & -0.0330 & 85.50 & 0.99 & 81.24 \\
\hline \multirow{9}{*}{$\underset{U}{U} N$} & 2 & 1 & 2 & 10 & $\begin{array}{l}-0.0158 \\
\end{array}$ & 54.34 & 1.11 & 81.06 \\
\hline & 8 & 1 & 4 & 10 & -0.0566 & 82.35 & 0.69 & 69.14 \\
\hline & 11 & 1 & 2 & 12 & -0.0072 & 51.92 & 1.27 & 82.25 \\
\hline & 17 & 1 & 4 & 12 & -0.0466 & 76.16 & 0.87 & 69.38 \\
\hline & 3 & 1.2 & 2 & 10 & -0.0111 & 76.05 & 1.06 & 117.30 \\
\hline & 6 & 1.2 & 3 & 10 & -0.0436 & 91.66 & 0.76 & 75.20 \\
\hline & 12 & 1.2 & 2 & 12 & -0.0031 & 73.68 & 1.23 & 142.60 \\
\hline & 15 & 1.2 & 3 & 12 & -0.0330 & 85.50 & 0.99 & 81.24 \\
\hline & 18 & 1.2 & 4 & 12 & -0.0503 & 102.61 & 0.80 & 70.84 \\
\hline
\end{tabular}

As a reminder, we want to maximize Poisson's ratio $v$ and the maximum traction force $F_{\max }$. Moreover, the maximum strain $\in_{\max }$ and the maximum stress $\sigma_{\max }$ must be minimized.

So, to reach the objectives the evaluation parameters must respect:

- Poisson's ratio $v \geq-0,0339$

- Maximum traction force $F_{\max } \geq 66.50 \mathrm{~N}$

- Maximum strain $\epsilon_{\max } \leq 0.97$

- Maximum stress $\sigma_{\max } \leq 75.56 \mathrm{MPa}$

In Table 6, the bolded evaluation parameters' values means that the value respect the objective in the respective parameters. The other values of evaluation parameters without bolded characters do not reach the formulated objectives.

To analyse of the DoE's results, classifying the action parameters in a specific order, let us the spotlight contradictions. These contradictions are illustrated in Table 6. First, focusing on the pair of simulations no. 6 and no. 15, we can underline the first generalized system of contradictions (GSC1). Indeed, in the simulation no. $6, F_{\max }, \in_{\max }$ and $\sigma_{\max }$ respect the objectives on the evaluation parameters whereas, in the simulation no. $15, v$ and $F_{\max }$ respond to the objectives. These two simulations are complementary to reach all the designated evaluation parameter's optimum levels. Indeed, the FEA no. 6 reaches a part of evaluation parameters' objectives and the FEA no. 15 reaches the other objectives. However, the configuration of these simulations is different. Although the action parameters $T 1$ and $T 2$ are identical between these simulations, the action parameter $L$ evolves in other terms, to respond to a portion of the objectives, $L$ must have a value of 10 $\mathrm{mm}$ and to respect the other portion of the objectives, $\mathrm{L}$ must have a value of $12 \mathrm{~mm}$. So, a first generalized physical contradiction (GPC) is present. Figure 27 illustrates and condenses the first generalized system of contradictions.

Following the same pattern, a second system of generalized contradictions (GSC2) can be underlined. For fixed values of the action parameters $T 1$ and $L$, the evolvement of the parameter's $T 2$ value leads to the reaches of all the objectives. It is the case between the simulations no. 2 and no. 8 ; no. 11 and no. 17 ; no. 3 and no. 6 ; no. 12 , no. 15 and no. 18 . These different cases lead to the same generalized physical contradiction. Indeed, in these 4 cases where $T 1$ are $L$ are fixed, the modification of the $T 2$ value brought about a solving to the unmet objectives.

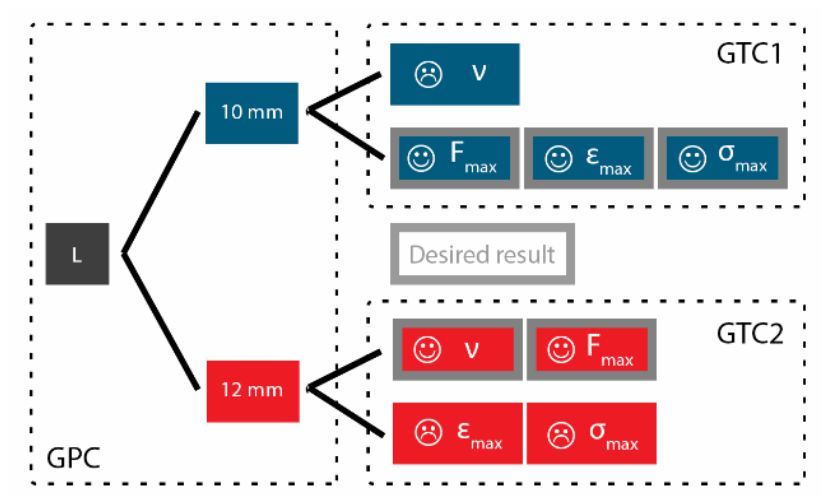

Figure 27. Generalized system of contradiction 1 with $T 1=$ $1.2 \mathrm{~mm}$ and $T 2=3 \mathrm{~mm}$

So, in the GSC1, it is the action parameter $L$ which contributes to the physical contradiction. The difference in the GSC2, the evolution of the parameter $T 2$ leads to the contradiction. The next step will be the solving of these physical contradictions with TRIZ based method. To help the solving of theses contradictions, a potential solution is to rely on several TRIZ separation principles as separation in time, separation in space, separation between parts and the whole, separation upon condition. The innovation way is to answer these contradictions working on the action parameters while optimizing all the evaluation para-meters at the same time.

\section{CONCLUSION}

In conclusion, in this paper, a method is proposed to characterize a new specific $3 \mathrm{D}$ auxetic structure with a parametric method. Usually, with conventional methods, a structure is built and its characterization is done by experiments or by FEA. In our case, our added value is that we propose a characterization of a parametric structure. This allows to optimize later the 3D structure for a specific industrial application. Indeed, knowing evaluation parameters' values requested for an industrial application, we can dimension the structure accordingly. 
To note, this article is the bootstrap of other future works to study in detail this structure. A possible next step is the transition between the optimization and the contradictions. Indeed, the multi-objective optimization step put forward an impossibility to optimize two parameters at the same time without a compromise. Moreover, contradictions could be underlined in this article. The contradictions solving is the next step of this study to obtain an inventive structure which can answer an industrial application. Using the TRIZ matrix, an analysis was able to highlight the most judicious principles to solve the underlined contradictions in this paper. According to this first analysis, two principles deserve to be studied: the dynamicity (principle no. 15) and the segmentation (principle no. 1). To solve the mentioned contradictions, a possibility is to rely on the segmentation principle, i.e. to divide the structure into independent parts. Moreover, to complete this approach, the dynamicity principle is able to be studied, i.e. to divide the structure into different parts capable of moving relatively each other, for example. Relying on these suggested principles, the contradictions can be potentially solved. This will allow to perform an inventive structure.

Moreover, the structure studied in this paper was printed on an additive manufacturing machine Stratasys Fortus250 mc with the FDM (Fused Deposition Modeling) technology and with an ABS (Acrylonitrile Butadiene Styrene) material (see Figure28).

For future prospects, this structure would be printed with a smoother material as a TPU with a SLA (Stereolithography) or SLS (Selective Laser Sintering) technology of printing. Traction/compression experiments would be done to compare the results obtained with the FEA method. Furthermore, to have a rigorous method, it would be interesting to print tensile specimens and to characterize these samples to have the 3D printed material law to implement it in the simulation models.

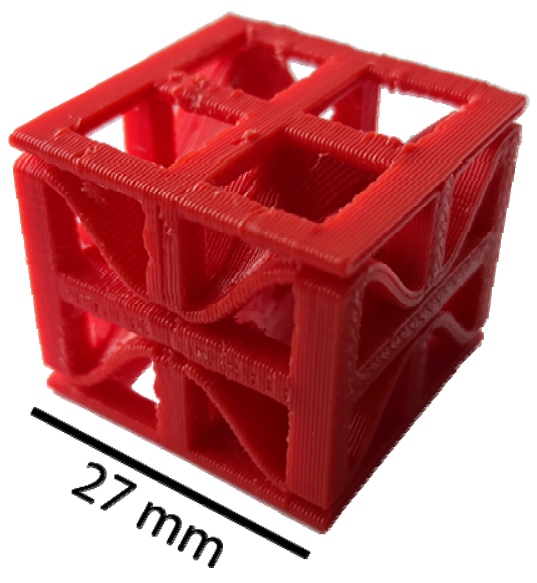

Figure 28. 3D 3D printed structure's sample with $T 1=1$ $\mathrm{mm} ; T 2=3 \mathrm{~mm}$ and $L=12 \mathrm{~mm}$

Furthermore, the studied lattice structure could be used in various industrial applications as a shockabsorber, for example. An assembly of the unit cell with a repetition in two directions was printed (see Figure 29). The exterior shape of the model is cylindrical to be consistent with the shock-absorber's standard shape. To note, we perform a cross section to see the interior of the structure. This printing is a beginning of future consideration to use the structure in real and concrete application.

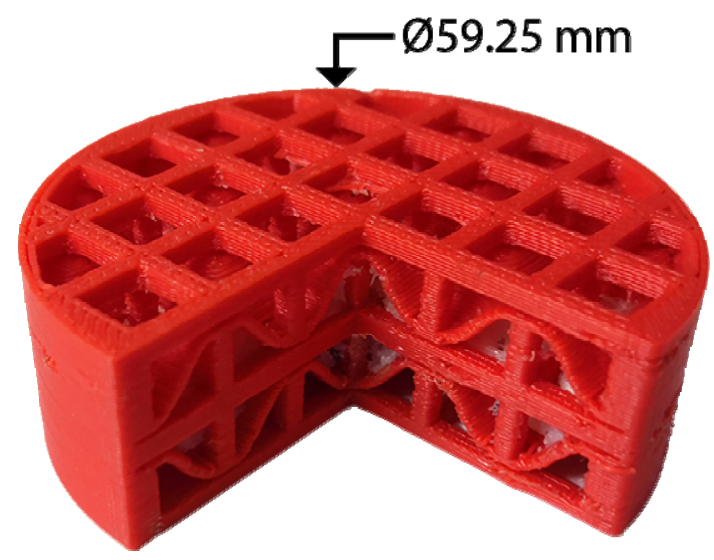

Figure 29. 3D printed structure built with the unit cell

\section{REFERENCES}

[1] R. Tino, M. Leary, A. Yeo, M. Brandt, and T. Kron, "Gyroid structures for 3D-printed heterogeneous radiotherapy phantoms," Phys. Med. Biol., vol. 64, no. 21, p. 21NT05, Nov. 2019, doi: 10.1088/1361-6560/ab48ab.

[2] Y. Xu, H. Zhang, E. Schlangen, M. Luković, and B. Šavija, "Cementitious cellular composites with auxetic behavior," Cem. Concr. Compos., vol. 111, p. 103624, Aug. 2020, doi: 10.1016/j.cemconcomp .2020 .103624 .

[3] S. Sun, N. An, G. Wang, M. Li, and J. Zhou, "Snap-back induced hysteresis in an elastic mechanical metamaterial under tension," Appl. Phys. Lett., vol. 115, no. 9, p. 091901, Aug. 2019, doi: 10.1063/1.5119275.

[4] A. Rafsanjani, A. Akbarzadeh, and D. Pasini, "Snapping Mechanical Metamaterials under Tension," Adv. Mater., vol. 27, no. 39, pp. 59315935, Oct. 2015, doi: 10.1002/adma.201502809.

[5] H. Yang and L. Ma, "Multi-stable mechanical metamaterials by elastic buckling instability," $J$. Mater. Sci., vol. 54, no. 4, pp. 3509-3526, Feb. 2019, doi: 10.1007/s10853-018-3065-y.

[6] H. Yang and L. Ma, "1D to 3D multi-stable architected materials with zero Poisson's ratio and controllable thermal expansion," Mater. Des., vol. 188 , p. 108430, Mar. 2020, doi: 10.1016/j.matdes.2019.108430.

[7] D. W. Abueidda, M. Elhebeary, C.-S. (Andrew) Shiang, S. Pang, R. K. Abu Al-Rub, and I. M. Jasiuk, "Mechanical properties of 3D printed polymeric Gyroid cellular structures: Experimental and finite element study," Mater. Des., vol. 165, p. 107597, Mar. 2019, doi: 10.1016/j.matdes .2019.107597.

[8] K. Meena, S. Singamneni, "A new auxetic structure with significantly reduced stress concentration effects," Mater. Des., vol. 173, p. 107779, Jul. 2019, doi: 10.1016/j.matdes. 2019.107779. 
[9] Y. Wang et al., "Numerical and experimental studies on compressive behavior of Gyroid lattice cylindrical shells," Mater. Des., vol. 186, p. 108340, Jan. 2020, doi: 10.1016/j.matdes.2019.108340.

[10] Y. Su, X. Wu, and J. Shi, “A novel 3D printable multimaterial auxetic metamaterial with reinforced structure: Improved stiffness and retained auxetic behavior," Mech. Adv. Mater. Struct., pp. 1-11, Jun. 2020, doi: 10.1080/15376494.2020.1774690.

[11] J. Goupy,Practice design of experiments (inFrench). Dunod, 2005.

[12] A. J. Keane, "Wing Optimization Using Design of Experiment, Response Surface, and Data Fusion Methods," J. Aircr., vol. 40, no. 4, pp. 741-750, Jul. 2003, doi: 10.2514/2.3153.

[13] N. Alagumurthi, K. Palaniradja, V. Soundararajan, "Optimization of Grinding Process Through Design of Experiment (DOE)-A Comparative Study," Mater. Manuf. Process., vol. 21, no. 1, pp. 19-21, Jan. 2006, doi: 10.1080/AMP-200060605.

[14] H. Chibane, A. Morandeau, R. Serra, A. Bouchou, and R. Leroy, "Optimal milling conditions for carbon/epoxy composite material using damage and vibration analysis," Int. J. Adv. Manuf. Technol., vol. 68, no. 5-8, pp. 1111-1121, Sep. 2013, doi: 10.1007/s00170-013-4903-3.

[15] H. Chibane, R. Serra, and R. Leroy, "Optimal milling conditions of aeronautical composite material under temperature, forces and vibration parameters," J. Compos. Mater., vol. 51, no. 24, pp. 3453-3463, Oct. 2017, doi: 10.1177/0021 998316687626.

[16] R. Serra, H. Chibane, and A. Duchosal, "Multiobjective optimization of cutting parameters for turning AISI 52100 hardened steel," Int. J. Adv. Manuf. Technol., vol. 99, no. 5-8, pp. 2025-2034, Nov. 2018, doi: 10.1007/s00170-018-2373-3.

[17] J. Goupy, Design of experiments for response surfaces (in French). Dunod, 1999.

[18] C. Wang, S. Zou, and W. Zhao, "Multi-objective optimization of a novel crash box with a threedimensional negative Poisson's ratio inner core," Proc. Inst. Mech. Eng. Part J. Automob. Eng., vol. 233, no. 2, pp. 263-275, Feb. 2019, doi: $10.1177 / 0954407017741780$.

[19] R. P. S. Oldenhuis, "Trajectory Optimization of a Mission to the Solar Bow Shock and Minor Planets," PhD Thesis, Delft University of Technology, 2010.

[20] J. Luo, Y. Yang, Q. Liu, X. Li, M. Chen, and K. Gao, "A new hybrid memetic multi-objective optimization algorithm for multi-objective optimization," Inf. Sci., vol. 448-449, pp. 164-186, Jun. 2018, doi: 10.1016/j.ins.2018.03.012.

[21] P. Ngatchou, A. Zarei, and A. El-Sharkawi, "Pareto Multi Objective Optimization," in Proceedings of the 13th International Conference on Intelligent Systems Application to Power Systems, ISAP'05,
2005, vol. 2005, pp. 84-91. doi: 10.1109/ISAP.2005.1599245.

[22] G. S. Altshuller, Creativity as an exact science: the theory of the solution of inventive problems. Gordon and Breach, 1984.

[23] G. Altshuller and A. M. Victory, "Algorithm of inventive problem solving (ARIZ-85C)," presented at the Methodological materials for trainees of the seminar" Methods of solving scientific and engineering problems"-L.: Leningrad Metal Works, 1985.

[24] G. S. Altshuller, L. Shulyak, and S. Rodman, The Innovation Algorithm: TRIZ, Systematic Innovation and Technical Creativity. Technical Innovation Center, 1999. [Online]. Available: https://books.google.fr/books?id=qV-3esXSZAEC

[25] F. Rousselot, C. Zanni-Merk, and D. Cavallucci, "Towards a formal definition of contradiction in inventive design," Comput. Ind., vol. 63, no. 3, pp. 231-242, Apr. 2012, doi: 10.1016/j.compind.2012.01.001.

[26] H. Chibane, S. Dubois, and R. DE GUIO, "Automatic Extraction and Ranking of Systems of Contradictions Out of a Design of Experiments: 18th International TRIZ Future Conference, TFC 2018, Strasbourg, France, October 29-31, 2018, Proceedings," in Automated Invention for Smart Industries, Springer, Cham, 2018, pp. 276-289. doi: 10.1007/978-3-030-02456-7_23.

[27] D. Cavallucci, F. Rousselot, and C. Zanni, "Representing and selecting problems through contradictions clouds," in Computer-Aided Innovation (CAI), Boston, MA, 2008, pp. 43-56.

[28] G. Cascini, P. Rissone, and F. Rotini, "From design optimization systems to geometrical contradictions," Proceeding ETRIA World TRIZ Future Conf., vol. 9, pp. 473-483, Jan. 2011, doi: 10.1016/j.proeng.2011.03.135.

[29] S. Dubois, I. Rasovska, and R. De Guio, "Interpretation of a General Model for Inventive Problems, the Generalized System of Contradictions," Jun. 2009. [Online]. Available: https://hal.archives-ouvertes.fr/hal-00395787

[30] S. Dubois, R. de Guio, and I. Rasovska, "From simulation to invention, beyond the paretofrontier," Jul. 2015. [Online]. Available: http://icube-publis.unistra.fr/4-DDR15

[31] L. Lin, I. Rasovska, R. De Guio, and S. Dubois, "Optimization Methods for Inventive Design," in TRIZ - The Theory of Inventive Problem Solving, D. Cavallucci, Ed. Cham: Springer International Publishing, 2017, pp. 151-185. doi: 10.1007/9783-319-56593-4 7.

[32] H. Chibane, S. Dubois, and R. De Guio, "Innovation beyond optimization: Application to cutting tool design," Comput. Ind. Eng., vol. 154, p. 107139, Apr. 2021, doi: 10.1016/j.cie.2021.107139.

[33] J. Sun, J. H. Frazer, and T. Mingxi, "Shape optimisation using evolutionary techniques in 
product design," Sel. Pap. 27th Int. Conf. Comput. Ind. Eng. - Part 2, vol. 53, no. 2, pp. 200-205, Sep. 2007, doi: 10.1016/j.cie.2007.06.010.

[34] Y. Wu, F. Zhou, and J. Kong, "Innovative design approach for product design based on TRIZ, AD, fuzzy and Grey relational analysis," Comput. Ind. Eng., vol. 140, p. 106276, Feb. 2020, doi: 10.1016/j.cie.2020.106276.

[35] J. Delgado-Maciel, G. Cortés-Robles, C. SánchezRamírez, J. García-Alcaraz, and J. M. MéndezContreras, "The evaluation of conceptual design through dynamic simulation: A proposal based on TRIZ and system Dynamics," Comput. Ind. Eng., vol. 149, p. 106785, Nov. 2020, doi: 10.1016/j.cie.2020.106785.

[36] M. Hanifi, H. Chibane, R. Houssin, and D. Cavallucci, "IPG as a new method to improve the agility of the initial analysis of the inventive design," FME Trans., vol. 49, no. 3, pp. 549-562, 2021, doi: $10.5937 /$ fme2103549H.

[37] R. Slim, R. Houssin, A. Coulibaly, M. Hanifi, and H. Chibane, "Framework for resolving problems resulting from lean integration from the early design phases of production 3D printing machine," FME Trans., vol. 49, no. 2, pp. 279-290, 2021, doi: $10.5937 /$ fme2102279S.

[38] R. Slim, R. Houssin, A. Coulibaly, and H. Chibane, "Lean system design framework based on lean functionalities and criteria integration in production machines design phase," FME Trans., vol. 49, no. 3, pp. 575-586, 2021, doi: 10.5937/fme2103575S.

[39] M. Hanifi, H. Chibane, R. Houssin, and D. Cavallucci, "Improving Inventive Design Methodology's Agility," in New Opportunities for Innovation Breakthroughs for Developing
Countries and Emerging Economies, Cham, 2019, pp. 216-227.

[40] M. Hanifi, H. Chibane, R. Houssin, and D. Cavallucci, "Contribution to TRIZ in Combining Lean and Inventive Design Method," in Systematic Complex Problem Solving in the Age of Digitalization and Open Innovation, Cham, 2020, pp. 280-291.

\section{НОВИ МЕТОД ЗА КАРАКТЕРИЗАЦИЈУ ПАРАМЕТАРСКЕ РЕШЕТКАСТЕ СТРУКТУРЕ}

\section{Р. Едуар, Х. Чибен, Д. Кавалучи}

Технички дизајнери често прилагођавају дизајн структуре функционалним потребама независно од капацитета дизајнираног техничког система како би понудили иновативне могућности. На основу концепта контрадикторности који постоји у ТРИЗ систему (руска скраћеница у теорији решавања инвентивног проблема), развијен је приступ реверзне изградње параметарске интелигентне структуре која потенцијално решава велики број инвентивних проблема. Предложена структура се ослања на нестабилност еластичног извијања. Изведен је параметарски CAD модел структуре и његово понашање је испитано помоћу анализе коначних елемената, базирањем на DoE. Предлаже се специфичан метод карактеризације и вишециљна оптимизација структуре. Циљ рада је да омогући техничком дизајнеру да брзо и инвентивно решава контрадикторни захтев да би га прилагодио индустријској примени. 